\title{
Uso e conservação da negramina (Siparuna guianensis Aubl.) em Bom Sucesso, Várzea Grande-MT*
}

\author{
Negramina (Siparuna guianensis Aublet.) use and conservation in Bom Sucesso, \\ Várzea Grande-MT
}

Utilisation et conservation de la negramina (Siparuna guianensis Aubl.) dans Bom Sucesso, Várzea Grande-MT

Uso y conservación del negramina (Siparuna guianensis Aublet.) en Bom Sucesso, Várzea Grande-MT

\author{
Carla Maria Abido Valentini** \\ Maria de Fátima Barbosa Coelho*** \\ Carmen Eugenia Rodríguez Ortíz** \\ Juliane Dias de Almeida**
}

Recebido em 10/8/2008; revisado e aprovado em 18/12/2008; aceito em 18/5/2009

\begin{abstract}
Resumo: Este trabalho teve como objetivo realizar um estudo da espécie medicinal Siparuna guianensis (negramina), na comunidade ribeirinha de Bom Sucesso, localizada no município de Várzea Grande - MT. Foi usada a entrevista semiestruturada com questões fechadas e/ou abertas e concluiu-se que sua principal forma de preparo é a decocção das folhas, utilizada na forma de banho para alívio da gripe, febre e dores no corpo, e que este conhecimento não está sendo repassado às novas gerações do local.

Palavras-chave : Plantal medicinal. Multidisciplinaridade. Conhecimento local.

Abstract: This work aimed to achieve an study of medicinal specie Siparuna guianensis (negramina) in the riverside community of Bom Sucesso, located in Varzea Grande-MT city. Using the semi-structured interview with closed questions and / or open, and concluded that its main form of preparation is a decoction of the leaves, used as a bath to relieve flu, fever and pain in the body, and that this knowledge is not being passed to new generations of the site. Key-words: Medicinal plant. Multidisciplinary. Local knowledge.

Résumé: Ce travail a eu comme objectif réaliser une étude de l'espèce médicinale Siparuna guianensis (negramina), dans la communauté marginale de Bom Sucesso, localisée dans la ville de Várzea Grande-MT. S'est utilisée l'entrevue semi-estruturada avec des questions fermées et/ou ouvertes, et s'est conclue que sa principale forme de préparation est la décoction des feuilles, utilisée dans la forme de bain pour soulagement de la grippe, de la fièvre et des douleurs dans le corps, et que cette connaissance n'est pas repassée aux nouvelles générations du lieu.

Mots-clés: Plantal médicinale. Muldisciplinaridade. Connaissance locale.

Resumen: Este trabajo tenía como objetivo para llevar con un estudio de la especie medicinal Siparuna guianensis (negramina), en la comunidad marginal Bom Sucesso, situada en la ciudad de Várzea Grande-TM. La entrevista de la mitad-structuralized fue utilizada con las preguntas cerradas y/o abiertas, y fue concluido que su forma principal de preparación es el decoction de leves, usado bajo la forma de baño para la relevación del grippe, de la fiebre y de los dolores en el cuerpo, y que no está siendo este conocimiento repassed a las nuevas generaciones del lugar.

Palabras clave : Plantal medicinal. Muldisciplinaridade. Conocimiento local.
\end{abstract}

\section{Introdução}

O termo "populações tradicionais" vem sendo cada vez mais utilizado nos meios acadêmicos e políticos, não mais com uma conotação pejorativa, vinculada à noção de atraso e subdesenvolvimento, como ocorria há algumas décadas, mas como baluarte de um pretenso "novo paradigma da moder- nidade: o desenvolvimento sustentável" (FLEURY e ALMEIDA, 2007).

Segundo afirma Diegues (2003), podemos entender o conceito de culturas tradicionais como aquelas associadas a modos de produção pré-capitalistas, ou seja, sociedades em que o trabalho ainda não se tornou uma mercadoria; nas quais há grande dependência dos elementos naturais e dos ciclos

\footnotetext{
* Parte da Tese de Doutorado da primeira autora no Programa de Pós-graduação em Agricultura Tropical da UFMT. ** UFMT, Programa de Pós-graduação em Agricultura Tropical/FAMEV. Av. Fernando Correa da Costa, s/n, Cuiabá, MT. CEP 78.060-900, E-mail: valentini@quimica.cefetmt.br.

*** UFERSA, Universidade Federal Rural do Semi-árido, Departamento de Ciências Vegetais, Programa de Pósgraduação em Fitotecnia, Km 47 da BR 110, Pres. Costa e Silva, CEP 59625-900, Mossoró, RN. Autora para correspondência: E-mail:coelhomfstrela@gmail.com.
} 
da natureza. A dependência do mercado existe, porém não é total:

as sociedades desenvolveram formas particulares de manejo dos recursos naturais que não visam diretamente o lucro, mas a reprodução social e cultural, como também percepções e representações em relação ao mundo natural marcadas pela idéia de associação com a natureza e dependência de seus ciclos. (DIEGUES, 2003, p. 82)

Ao longo das muitas gerações, tais populações acumularam conhecimentos de sua natureza próxima, vivenciada, desenvolvendo capacidade ímpar de interferir no ambiente de forma sustentável (NORDI et al., 2001). Dessa forma, a diversidade biológica foi sendo mantida de forma conjunta com a diversidade cultural dessas populações.

As comunidades tradicionais, em função da forte influência do meio natural, apresentam modos de vida e cultura diferenciadas, e seus hábitos estão diretamente submetidos aos ciclos naturais. A forma como apreendem a realidade e a natureza é baseada não só em experiência e racionalidade, mas em valores, símbolos, crenças e mitos (MONTELES e PINHEIRO, 2007).

A etnobotânica desponta como o campo interdisciplinar que compreende o estudo e a interpretação do conhecimento, significação cultural, manejo e usos tradicionais dos elementos da flora (CABALLERO, 1992), buscando, portanto, resgatar e preservar os conhecimentos tradicionais das pessoas em relação às espécies, seus usos, manejos e relações com o ambiente. Compreende então o estudo das sociedades humanas, passadas e presentes, e suas interações ecológicas, genéticas, evolutivas, simbólicas e culturais com as plantas (HEIDEN, 2006; FONSECAKRUEL e PEIXOTO, 2004; ALVES et al., 2007). De acordo com Hanazaki (2003), a etnobotânica pode ser compreendida como o estudo das interações entre pessoas e plantas, revelando a grande importância dos recursos vegetais para a sobrevivência e manutenção de populações locais. Nesse sentido a etnobotânica da negramina (Siparuna guianensis Aubl.) - Siparunaceae compreende as interações estabelecidas pelas populações tradicionais com esta espécie, ao longo das diversas regiões em que ocorre, refletindo o conhecimento local acumulado.
Segundo Renner \& Hausner (2005), em muitos países da América, a decocção de folhas da S. guianensis é usada como uma bebida contra as desordens estomacais. As folhas são usadas também em compressas ou cataplasmas contra dor de cabeça e reumatismo. No Panamá e Guiana, extratos são usados para matar insetos daninhos ou como inseticidas. Na Guiana, suas folhas são também usadas para preparar armadilhas para peixes devido ao típico odor de sua espécie, que disfarça o cheiro humano. Nas vizinhanças do Suriname, o decocto feito das folhas é usada como uma bebida ou para um banho depois do parto. Vigneron et al. (2005), num estudo na Guiana Francesa com diferentes grupos e nacionalidades (Criolos, Palikur, Galibi, Brasileiros, e Europeus), encontraram que as folhas de Siparuna guianensis combinadas com folhas de Campomanesia spp. são usadas como remédio antimalária.

No Amazonas, região das Guianas, as folhas são preparadas como chá e tomadas para febres, pressão arterial alta, para doenças reumáticas e também contra cólicas (PRANCE, 1972; SANTOS e PEIXOTO, 2001). A tintura da folha é muito apreciada para tratar machucados e inchaços. Os índios Palikur usam externamente as folhas moídas com sal para o preparo de um cataplasma anti-inflamatório, ou o seu decocto para uso na forma de banho durante o parto. Os índios de Wayãpi no Amazonas tomam um decocto das folhas e da casca do caule para frios, gripe e febre, administrando-o oralmente em pequenas quantidades, mas principalmente na forma de banhos (LORENZI, 2002).

Ainda no Amazonas, os índios Tikuna comem os frutos para dispepsia e indigestão; os Kubeo usam as folhas para mordedura de serpente e fazem um chá das frutas para aliviar congestão nasal e frios; os Waorani esmagam as frutas e folhas para fazer uma mistura pungente que é esfregada no rosto e cabeça para tratar "dor de cabeça de febre", e uma infusão das folhas é empregada como febrífugo (LORENZI, 2002). Os índios Tacana, grupo étnico boliviano do Amazonas, usam uma decocção das folhas como uso externo para gripe (BOURDY et al. 2000). Os índios Yanomami cheiram as 
folhas amassadas, e esfregam em suas cabeças e corpos para vertigem (MILLIKEN e ALBERT, 1996).

O uso de $S$. guianensis tem sido relatado com frequência em diversos estados brasileiros. Rodrigues et al. (2002), citam o uso da espécie pela população de Luminárias, Minas Gerais, como tendo poderes sobrenaturais, em banho de descarrego e, no mercado de Madureira-RJ, segundo Arjona et al. (2007), a espécie também é vendida para esta finalidade.

$\mathrm{Na}$ comunidade Mumbuca, em Jalapão, no Tocantins, faz-se o uso de sua infusão como analgésico (ROCHA-COELHO e SANTOS, 2008). Na região do Alto do Rio Grande, em Minas Gerais, faz-se uso do decocto ou infusão de toda a planta como anti-inflamatório, carminativo, estimulante, na cefalalgia, nas gripes, resfriados e sua cataplasma, compressa ou banho é usada para reumatismo (RODRIGUES e CARVALHO, 2001). Souza \& Felfili (2006), também citam seu uso pela população de Alto Paraíso de Goiás para coluna, reumatismo e artrite. Em estudos nas comunidades rurais limítrofes à Reserva Biológica de Poço das Antas, no Rio de Janeiro, faz-se uso de seu caule como combustível. Nessas comunidades, o caule fornece a lenha para alimentação dos fogões, fornos e tachos para o beneficiamento de produtos agrícolas (CHRISTO et al. 2001; PINTO SOBRINHO, 2007).

No estado de Mato Grosso foram realizados alguns estudos etnobotânicos com a espécie, e neles ela é citada pelo nome popular de negramina. Carmona e Guarim Neto (2001) relataram que no leste do estado as folhas da espécie são utilizadas na forma de banho para sinusite. Souza (1992) também relata em sua pesquisa com moradores da comunidade ribeirinha do Coxipó do Ouro o uso das folhas em banho para dores no corpo. No Alto Coité, em Poxoréo, as pessoas utilizam um semonte - folhas secas junto ao fogo, moídas e misturadas ao fumo ou puras, para cheirar e uso tópico - para curar "malina", que é descrita como uma dor de cabeça causada pela exposição demasiada ao sol, que provoca corrimento de sangue nasal (SOMAVILLA, 1998). No Vale do Aricá, município de Cuiabá, as folhas são utilizadas na forma de chá e banhos para fraqueza e também para malina (PASA, 1999), e na Aldeia Pakueran, em Paranatinga, as folhas são fervidas e utilizadas em banho para febre e "quentura" na cabeça, espécie de enxaqueca (SCHIMOLLER, 1997). Em Nova Xavantina, o sumo de suas folhas com mastruz (Chenopodium ambrosioides) é relatado como medicinal para pós-operatório. Suas folhas são utilizadas como repelentes nos galinheiros para piolho de galinha, $\mathrm{e}$ também para uso em rituais espirituais (DUARTE, 2001). Fontelle (2001) relatou as indicações de raizeiros, que recomendam o uso da folha na forma de decocto e infuso para malina, resfriado e banho de descarrego para mau-olhado, podendo para isso ser associada à quina, assim como para hipetermia e hemoptise.

Muitas sociedades tradicionais possuem uma vasta farmacopéia natural, proveniente dos recursos vegetais encontrados nos ambientes naturais e, atualmente, é importante avaliar a interação destas populações com os recursos naturais de que dispõem (AMOROZO, 2002). Assim, o objetivo deste estudo foi verificar o interesse, a forma de exploração e uso da S. guianensis por moradores de uma comunidade ribeirinha, em Bom Sucesso, no município de Várzea Grande, estado de Mato Grosso.

\section{Materiais e Métodos}

Área de estudo

A comunidade ribeirinha Bom Sucesso $\left(15^{\circ} 42^{\prime} 54,23^{\prime \prime} S\right.$ e $\left.56^{\circ} 06^{\prime} 21,64^{\prime \prime} \mathrm{O}\right)$ é um dos distritos do município de Várzea GrandeMT criado pela lei n. 126, no dia 23 de dezembro de 1948, e confirmada por lei 9.583 no dia 24 de dezembro de 1948, situada às margens do rio Cuiabá, a $152 \mathrm{~m}$ metros acima do nível do mar (Figura 1).

O município de Várzea Grande, com extensão territorial de $949,53 \mathrm{~km}^{2}$, está localizado no Estado de Mato Grosso, fazendo limites com as cidades de Cuiabá, Acorizal, Jangada, Santo Antônio do Leverger e Nossa Senhora do Livramento, tendo sido designada pelo Projeto Radambrasil (1982) como uma região da Depressão Cuiabana.

A estimativa da população de Várzea Grande, segundo o Instituto Brasileiro de 
Geografia e Estatística, (IBGE) para 2004, foi de 242.674 habitantes, e para Bom Sucesso, de 2.757 habitantes, sendo 2.211 na zona rural e 546 na zona urbana.

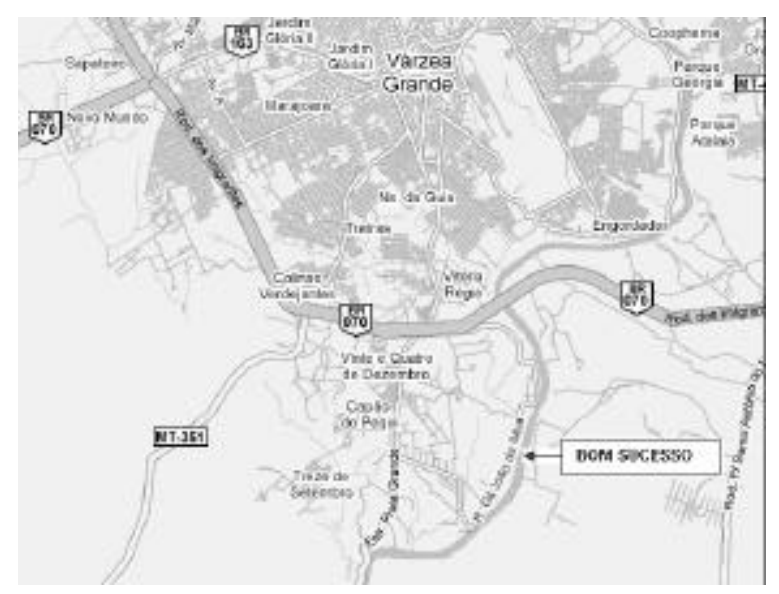

Figura 1 - Localização do Distrito de Bom Sucesso no Município de Várzea Grande-MT. Fonte: http:/ / maps.google.com.br (modificado).

Do ponto de vista geomorfológico, a região possui a topografia rebaixada em torno de 150 a 200m de altitude, sendo caracterizada por relevo de planície, desenvolvido sobre rochas pré-cambrianas fortemente deformadas (FUNASA, 2007).

O clima de Várzea Grande está na categoria Aw da classificação de Köppen, tropical semi úmido. Caracteriza-se por apresentar duas estações bem definidas: a seca, que vai de abril a outubro, e a chuvosa, que vai de novembro a março. A pluviometria média anual da região oscila em torno de $1.350 \mathrm{~mm}$, com sazonalidade marcada por dois períodos bem distintos: no verão, verificam-se os maiores índices pluviométricos, que oscilam entre 1.000 e $1.500 \mathrm{~mm}$ e na, estação seca, a precipitação chega a ser quase nula. (INMET, 1996, p. 1997).

A temperatura média anual é de $26^{\circ} \mathrm{C}$, com temperaturas mínimas próximas a $15^{\circ}$ $\mathrm{C}$, em julho e, máximas superiores a $32^{\circ} \mathrm{C}$, em outubro. A umidade relativa do ar varia muito, com a média anual em torno de $74 \%$ (FUNASA, 2007).

O solo é classificado como argissolo vermelho amarelo distrófico, de textura arenosa/média (MACHADO et al., 2009). A vegetação é composta por savana arbórea aberta (cerrado), capoeira e mata ciliar (OLIVEIRA, 2008).
Bom Sucesso está situada a 15 quilômetros do centro de Várzea Grande, é um lugarejo formado por ruas estreitas, com sua rua principal, paralela ao rio, com mais de um quilômetro de extensão, calçada com blocos de cimento e ladeada por casas, geralmente próximas umas das outras, com poucas cercas ou muros, quintais grandes e arborizados, e portas que se abrem no passeio, onde as pessoas costumam sentar (CAMPO, 2006).

Nessa rua principal, podem-se ver as peixarias e os engenhos e, sobre as fornalhas, grandes tachos de cobre nos quais fazem rapadura. Vê-se mais: bois pastando nos espaços verdes e, ao fundo, o rio Cuiabá e seus pescadores em suas estreitas canoas, vê-se a mata ciliar, ainda preservada (CAMPO, 2006).

O distrito, hoje, tornou-se rota turística, porque os restaurantes instalados à beira do Rio Cuiabá servem os peixes da cozinha tradicional, verdadeira atração turística de toda a região, além das rapaduras ali fabricadas que são também atrativos de Bom Sucesso.

\section{Coleta de dados}

Os dados foram coletados nos meses de outubro e novembro de 2008 , sendo aplicada a técnica de entrevistas semiestruturadas (ALBUQUERQUE et al., 2008), cujas questões compreenderam os aspectos socioeconômicos, culturais, conhecimento e uso da negramina (S. guianensis), gravadas em fita microcassete (Gravador Olympus mod. Pearlcorder S701) com a permissão dos entrevistados, escolhidos primeiramente ao acaso, com questões fechadas e/ou abertas (Anexo 1), e depois intencionalmente, para que se tivesse uma abrangência das diferentes faixas etárias da comunidade, de forma a investigar a transmissão do saber local dos mais velhos para os mais novos.

\section{Resultados e Discussão}

Aspectos socioeconômicos

Foram entrevistadas 24 pessoas da comunidade; 13 homens e 11 mulheres, sendo 20 deles nascidos e criados em Bom Sucesso, 
dois nascidos em outras comunidades da Várzea Grande (Engordador e Pai André), um em Cáceres-MT, e outro em Cuiabá-MT, porém esses que não nasceram moram no local desde que se casaram ou foram criados lá. Segundo Coradini (2006), em Bom Sucesso, a construção da identidade se dá nas relações de acontecimentos passados importantes para essas pessoas. Segundo Gimènez (2000) esta seria a identidade histórica e patrimonial, pois os moradores, em sua grande maioria, são todos nascidos nesses lugares, assim são poucos os "estranhos", como são chamadas as pessoas que não nas- cerem nas comunidades, prevalecendo os laços de consanguinidade, que aliados a outros fatores, consolidaram práticas sociais e culturais que foram passadas de geração em geração e que ainda fazem parte da vida das pessoas.

A faixa etária variou de 15 anos a mais de 86 , mas a faixa de 66 a 75 anos correspondeu ao maior número de entrevistados $(29,2 \%)$, conforme verifica-se na Figura 2. Resultados semelhantes foram encontrados em Caruaru-PE, por Florentino \& Albuquerque (2007), onde a idade dos entrevistados variou entre 20 e 80 anos.

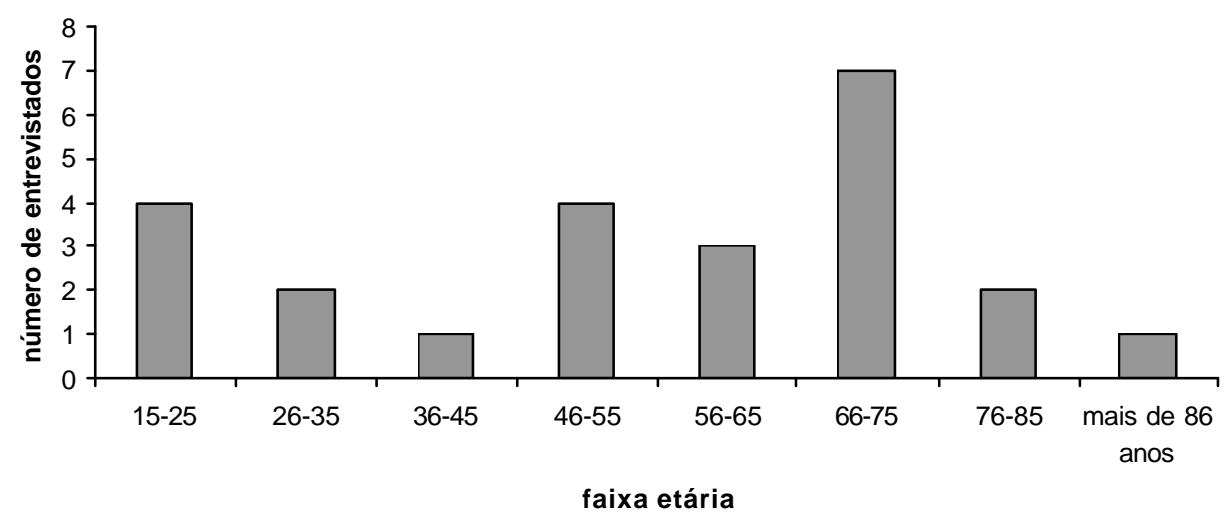

Figura 2 - Faixa etária dos entrevistados em Bom Sucesso, Várzea Grande-MT.

A maioria dos entrevistados estudou em Bom Sucesso, sendo que mais da metade deles cursou apenas os quatro primeiros anos escolares.

Dos entrevistados, mesmo os aposentados e os do lar ainda trabalham, ajudando no sustento da família, fazendo rapadura,

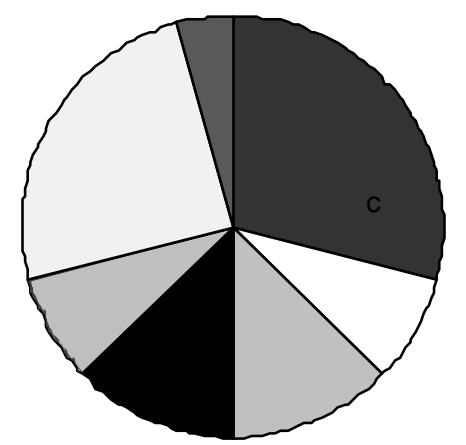

na roça, na criação de animais, na pescaria de subsistência, fazendo "bicos" nas peixarias do local, ou seja, todos têm uma história relacionada ao Rio Cuiabá, e as atividades que construíram no local relacionadas em torno dele. As atividades de comércio englobam a venda de rapadura (Figura 3).

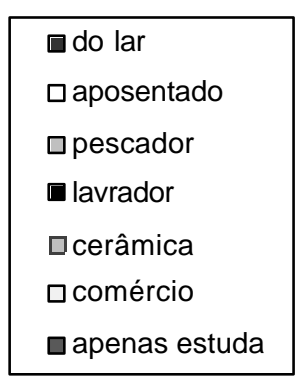

Figura 3 - Atividades dos entrevistados em Bom Sucesso, Várzea Grande-MT.

A relação com o rio Cuiabá é de tal importância que seu Joaquim, conhecido como Painha, terminou a entrevista dizendo em tom de preocupação: “O Rio está mor- rendo, está no hospital, está na UTI..."

Esse conhecimento, esse saber que os pescadores desenvolveram ao longo da história com o meio ambiente, nos dá lições de 
como transpor a própria sina, pois os homens e mulheres da pesca artesanal existem e resistem fortalecidos pelo aprendizado de como conservar e manejar sustentavelmente os recursos naturais e a biodiversidade, desenvolvido ao longo de gerações com a natureza (SILVA, 2007). Por tal importância, e pelas entrevistas terem permitido que as pessoas se expressassem sobre o lado histórico e cultural, a seguir algumas falas que exemplificam a tristeza que sentem ao comparar o Rio Cuiabá de ontem e de hoje, e o conhecimento das causas da morte desse Rio, que não poderiam deixar de ser registradas.

[...] peixe: tem poco, poco, poco... Das quatro da manhã até sete e meia não dá nada... O Rio manso acabou com o Rio Cuiabá... O Rio Manso criou seca... O Rio Cuiabá não cria o peixe, no Rio manso que cria o peixe... Oia eu pegava peixe aqui... dava demais de peixe, ficava peixe ai que não tinha pra quem vendê, pra quem dá... (Nhá Dita, 91 anos)

[...] pega agora só piau... Lá no pantaná que cria o peixe... (D. Genil, 54 anos)

Pesco quando dá folga... Pego pra comê e vou embora... Na época das água pega pintado... agora piau, geripoca... fechô a barragem lá acabou... (Seu José Narciso, 61 anos)

Aqui relacionam a falta de peixe do rio Cuiabá com a construção da barragem do rio Manso, em 1999. Sendo assim, o nível máximo do Rio Cuiabá a partir desta data passou a ser determinado pela APM-Manso e como provável consequência, algumas áreas deixarão de ser inundadas. O rio Manso é o principal formador do Cuiabá, um dos rios pantaneiros mais importantes. Os peixes que fossem subir para desovar vão encontrar na hidrelétrica um obstáculo intransponível.

\section{Conhecimento, uso, manejo e conservação de $S$. guianensis}

Dos entrevistados $66,7 \%$ conhecem e ainda usam a $S$. guianensis, $12,5 \%$ conhecem, mas não fazem mais uso, $12,5 \%$ já ouviram falar, mas nunca usaram, e 8,3 nunca nem ouviram falar. Constatou-se que o conhecimento dos mais velhos sobre a $S$. guianensis, não está sendo assimilado pela geração mais jovem que, na sua maioria, alegou não conhecer e nunca ter usado, ou ter abandonado o uso da espécie.

Dos entrevistados que fazem ou faziam uso da negramina, todos disseram que cozinhavam as folhas da planta, esperavam esfriar e usavam na forma de banho, indicado para algumas enfermidades e sintomas descritos na Figura 4 que também mostra o número de citações pelas pessoas.

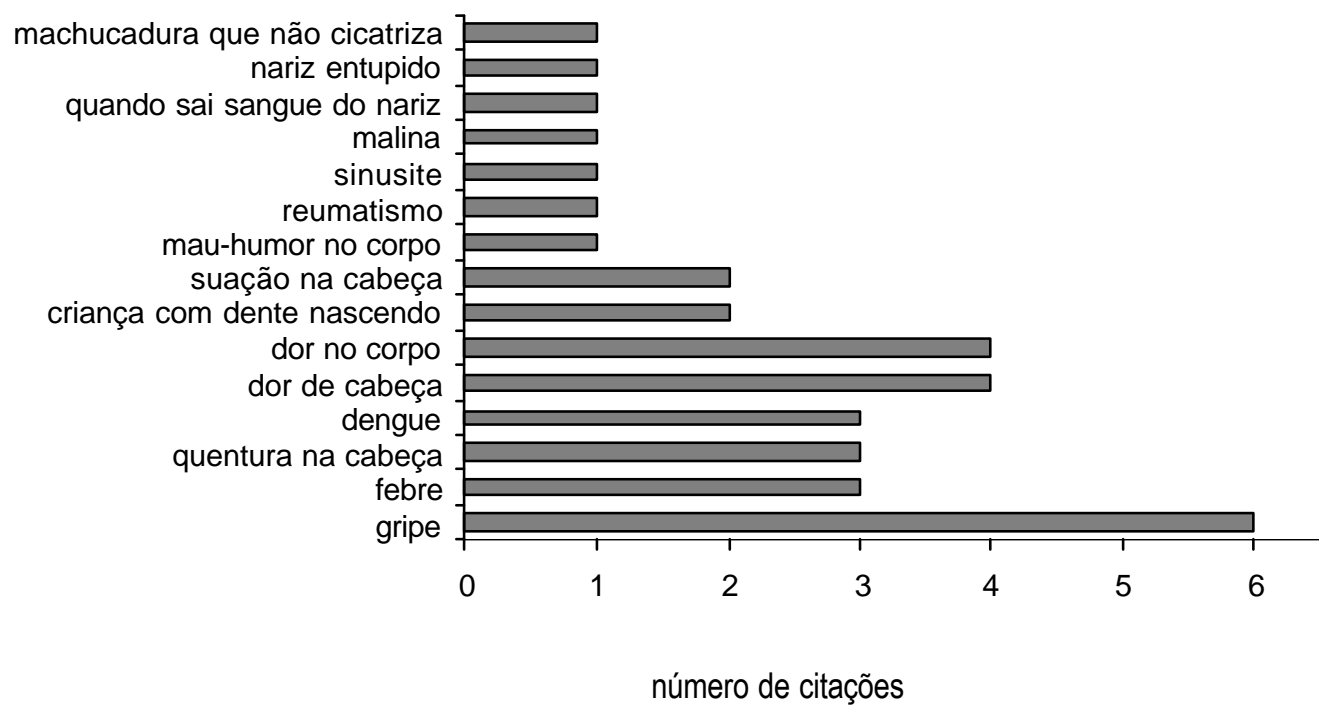

Figura 4 - Uso medicinal citado pelos entrevistados, em Bom Sucesso, Várzea Grande-MT.

As citações das enfermidades foram transcritas da forma como foram anotadas nas entrevistas, e a seguir, alguns trechos dessas transcrições relatadas pelas pessoas que ainda usam S. guianensis. São as pessoas mais idosas, que são as detentoras das informações passadas de gerações anteriores, e que formam verdadeiros núcleos de resistência 
perante as mudanças que se impõem na comunidade.

Remédio assim pra banho pra criança, pra pessoa que sofria de dor de cabeça é ideal. Folha e galho pra tomar banho, pra beber é ruim... ruim ruim, ruim mesmo... Pra febre vai sarar, pra gente que tem quentura na cabeça...

[...] Tradição, a medicina era difícil, o primeiro socorro era o mato, a gente passa... (Seu Painha, 78 anos)

Desde menina já pegava pra dar banho no criança quando tá com gripe... a folha... Vi minha mãe fazer. (D. Lucinda, 68 anos)

Refresca a cuca, febre.... é bão cozinhá a folha.... Folha dele com erva de bicho, chá de frade... tá com gripe muito forte, febre, banho dele, toma com quarqué comprimido é bom demais... bebe um bocadinho não tem problema... Os avó fazia, a gente acompanha a direção certa... (Seu Cirilo, 73 anos)

Remédio pra tomar banho lavar cabeça de criança, cheiroso... não usa pra beber, só pra tomar banho, minha mãe me ensinou... quentura na cabeça, quando tá nascendo dente... (D. Maria Clara, 71 anos)

Dá banho no criança, assim desde a cabeça, pra modi febre, as coisas assim que criança tem... (D. Zulmira, 81 anos)

A folha é bom pra dengue, toma banho... Pra criança quando tá muito gripada, tá com nariz entupido, ao invés de fazer aerosol toma banho com negramina... Eu cozinho pra dar banho na criança, até mesmo pra mim... (D. Teonila, 75 anos)

Negramina ébom pra malina, pra dar banho no criança [...] Malina dá de sol, pessoa que pega muito sol, dá suação na cabeça. (Nhá Dita, 91 anos)

[...] cozinha pra fazê banho, pro causa de gripe, pra lavar cabeça, né... Aprendi usar com minha mãe... (D. Buguela, 70 anos)

Ela é usada mais pra banho, as vez a pessoa tem assim um mau-humor no corpo, dor no corpo, uma espécie assim de um reumatismo... (Seu Fião, 68 anos)

[...] cozinha, deixa ele fria, e depois nois lava a cabeça que é bom pra malina. (Seu Davi, 58 anos)

Preparo, uso pra tomar banho pra dor na cabeça, das vez sai sangue do nariz, toma banho de cabeça [...]. (Seu Arlindo, 59 anos)
Esta predominância de uso tópico em banho para malina repete-se nos estudos feitos por Carmona e Guarim Neto (2001), no leste do estado; Souza (1992) no Coxipó do Ouro; Somavilla, (1998) em Poxoréo; Pasa, (1999), no Vale do Aricá e Schimoller, (1997) na Aldeia Pakueran, em Paranatinga.

Das pessoas que citaram o banho com negramina, três recomendaram este banho à noite, e que, após o mesmo, deve-se fazer dieta, ou seja, deve-se rebuçar e só sair no outro dia.

Minha mãe fazia com nois... a criança tava com febre, aquela febre que não cortava, aquele que se pegava nele assim, tava com olho vermelho [...] a mãe fazia o remédio, era esse aí... fazia o chá de negramina, banho da negramina, mas não podia pegar vento... porque ele é quente, dava o banho na criança, enleava ele, guardava ele, dava um melhoral infantil, anador, noutro dia a gurizada tava correndo, cortava febre, cortava dor, cortava tudo [...]. (Seu José, 54 anos)

Cozinha a folha, só que ele é um pouco quente, ai deixa ela amorná, ai fica bem fresquinha... ai vamos supor [...] é melhor tomar assim num lugar aberto, ai outro dia cedo não toma banho na água fria, deixa aquilo passá [...]. (Seu Fião, 68 anos)

Minha mãe ensinou uma amiga a tomar banho de cabeça inteira, e entrar embaixo de um pano, pois ela sarou [...] ela tinha muita dor de cabeça [...] mas tem que ter a dieta, porque ela é quente [...]. (D. Lucila, 40 anos) $\mathrm{Um}$ dos entrevistados recomendou cozinhar as folhas da negramina com erva de bicho e chá de frade para gripe, outro disse que o banho é melhor se misturar as folhas de negramina com erva de bicho, folhas de tamarindo e folhas de eucalipto, e um terceiro ensinou a usar ela cozida com um pouco de sal. Apenas dois disseram que pode beber o chá, mas que é ruim.

Três entrevistados citaram também o uso da casca dos galhos em vinho branco para reumatismo:

A casca da madeira, eu já até tomei ele... diz que pra coluna, no vinho branco... (D. Lucinda, 68 anos)

Um senhor daqui usa a casca pra por no vinho... diz que é muito bom pra reumatismo. (D. Teonila, 78 anos)

[...] cunhado pegô pro pessoal de Várzea Grande... casca põe no vinho pra reumatismo... (Nhá Dita, 91 anos) 
O uso contra o reumatismo, apesar de não ser frequente, também foi relatado nas Guianas por Prance, (1972); Santos e Peixoto, 2001 e por Renner e Hausner (2005).

Mesmo que não utilizem mais a negramina, alguns entrevistados mantêm viva a memória de seu uso e explicam o que aprenderam com seus pais e avós:

A negramina, antigamente, o pessoal, minha mãe, minha avó [...] em uma machucadura, uma dor de cabeça, naquela época quando a criança saia pra brincar, e vamos supor tinha uma cortadura que tava demorando pra cicatrizar, ai fazia a negramina, cozinhava e lavava com ele, e cicatrizava. Minha mãe usava muito pra dor de cabeça, assim... pegava a negramina, moiava o pano e punha na testa aquele pano moiado, dormia, no outro dia tava bom.Se especialmente mulher tava com dor de cadeira, dores no corpo, chá de negramina, e banho com sal, deixava esfriar, punha o sal, fazia aquela salmora com negramina, rebuçava a pessoa, no outro dia a pessoa suava e a febre ia embora. (Seu José, 54 anos)

Aprendi com minha mãe[...] Cozinha a folha e dá banho na cabeça, modi falava malina lá no sitio, pra modi dor na cabeça... (D. Ana Maria, 47 anos)

Meu pai me ensinou [...] a gente tá com gripe, com aquela dor no corpo, mistura com outras foias do mato, esse erva de bicho, que dá nesse lugar de brejo,e aquele folha de tamarino, eucalipto, a gente faz aquele banho, mistura tudinho e põe na panela com água e põe pra ferver no fogo, toma banho com caneca, de cabeça...toma mais é à tarde, e a noite não sai de casa. (Cirilo Filho, 27 anos).

A área de coleta pela comunidade era mais acessível antigamente. Apesar de o rio Cuiabá e além-margem não serem mostrados como limites do território para a comunidade, uma das justificativas para o abandono do uso desta espécie é a distância que a comunidade tem que percorrer para buscá-la, pois é unânime, nas entrevistas, que a negramina só é encontrada do outro lado do rio, próximo ao Morro de Santo Antônio, ou seja, necessitam de canoa e ainda andar alguns quilômetros a pé para chegar ao local. Além da alegação de alguns que o local foi loteado e cercado, muitos já estão idosos, dependem de outras pessoas para buscarem a planta, e nem sempre há esta disposição dos mais novos que acham mais fácil comprar um remédio na farmácia.

Reconhecido como patrimônio histórico, cultural e ambiental pela lei estadual 7.381/01, de 2002, o Morro de Santo Antônio $\left(15^{\circ} 45^{\prime} 58,64^{\prime \prime} \mathrm{S}\right.$ e $\left.56^{\circ} 05^{\prime} 45,50^{\prime \prime} \mathrm{O}\right)$ está localizado às margens do rio Cuiabá, a 500 metros do nível do mar, no município de Santo Antônio do Leverger. Em relação a Bom sucesso está do outro lado da margem do rio.

Um morador, que é bisneto do fundador da comunidade, seu Petrolino, conhecido como Fião, dá uma descrição de como conheceram e como era o local de coleta:

A gente campeava, a gente tinha umas criação... na oportunidade de campear é que a gente conheceu esse lugar... tinha uma comunidadezinha por nome Guanami,que fica logo pertinho lá, pertinho desse corgo, travessa o corgo Cascavel, já logo tá chegando pertinho do Guanami. Era um comunidade de 4 a 5 moradores... Hoje lá eles venderam, é uma fazendinha lá... Dá pra chegar de a pé, de cavalo, hoje lá já ficou o local, já é fundo do loteamento da Cachoeira de Pólvora, por aqui parece 2 horas, distância quase daqui na Várzea Grande.

Os moradores apontam encontrá-la próximo a um córrego, e em campo aberto, mas não na beira do rio. A seguir, alguns depoimentos de outros entrevistados sobre o local onde a espécie é encontrada e que deixam claro que é do outro lado do rio, próximo do morro de Santo Antônio.

A negramina nós temos lá do outro lado do rio, lá perto do morro tem um Córrego do Morrinho, chamado de Cascavel. Chega do outro lado de canoa, leva umas 3 horas. (Seu Painha, 78 anos)

Oia nois pegava lá do outro lado do rio, mas agora faz muito tempo que não pego [...] Ficou difícil venderam pra lá, ficou tudo loteado, cercaram [...] Oia num sei faz muitos anos que não vou pro outro lado [...] É pranta de campo, ele nasce na terra do campo, não nasce na beira do rio... Atravessa de canoa e anda um pedação. (D. Lucinda, 68 anos)

Negramina, lado de lá do rio...Cerração.... na beira do corgo sempre tem ele. Ele é nativo, dá no campo, 2, $3 \mathrm{Km}$ da beira do rio. (Seu Cirilo, 73 anos)

Beira do morro de Santo Antônio... Eu nunca fui ... (D. Ana Maria, 47 anos)

Longe...pé do morro.. Mato cerrado, não dá perto do rio... Quando eu casei meu marido 
ia lá pegar [...] Antigamente usava, agora nem num usa mais [...] vizinho meu manda pegar pra mim. (D. Maria Clara, 71 anos)

Do outro lado do rio, sempre tem gente que vai pra lá... eu mesmo quando vou arrancar minhoca lá pra esse lado eu pego... (Seu Donato, 47 anos)

Ah... negramina é longe, fica perto da estrada de Santo Antônio [...] Barco e ai anda 3500 metros... vai de manhã e chega meio di a[...] Quem sempre panha pra mim é o meu véio quando ele vai pra lá dar uma olhada no terreno. (D. Teonila, 75 anos)

Aui! A gente vai bem longe pra pegá ...Tem vez quando a gente qué, tem uma dona que mora do outro do rio, a gente encomenda pra ela, ela acha que fica mais fácil do que pra nois ir daqui lá pegá...Ela traz pra gente... (D. Genil, 54 anos)

A negramina só tem numa região aqui, que nois fala é... cascavel, do outro lado do rio, somente lá. Quando a pessoa tem necessidade, ai fala com esse meu primo, ele vai lá e pega aquela quantia... (Seu Fião, 68 anos)

Se encontra longe... lá naquele morro é que tem ele [...] Ela não dá em beira de rio, só no campo mesmo. Atravessa de canoa e depois anda a pé... Nós iamos uma turma, agora o pessoal tá recuando de ir lá.... não sei, eu mesmo faz 3 anos que não vô... agora vai gente, mais muito pouco... (Seu Davi, 58 anos).

Nesse mundão pra lá ...perto da estrada de Santo Antônio , pra lá que pega.. Pra ir lá tem que ir de canoa, e depois anda a pé... (D. Buguela, 70 anos).

Do outro lado do rio que tem... Quando não é eu, é o meu irmão que pega também... (Cirilo Filho, 27 anos)

Sobre a época de coleta, três entrevistados disseram sobre a antiga tradição de pegar a negramina na Semana Santa para o ano inteiro, dois recomendaram em qualquer época depois da brotação, e os demais em qualquer época. Como apenas quatro entrevistados afirmam conhecer a flor da espécie, e apenas dois o fruto, supõe-se que fazem a coleta da negramina no seu estágio vegetativo. Vale ressaltar que pelo acompanhamento da fenologia da espécie em Cuiabá, a semana de Páscoa coincide com o período vegetativo da espécie, após a queda de frutos que ocorre em fevereiro e março.
A gente ia na Semana Santa naquele morro... naquele morro tem medicina... lá que tem... [...] na Semana Santa porque é tradição, o remédio é mais forte... sei lá... a gente obedecia o que os mais veio falava, agora a gente pega qualquer hora. (Seu Painha, 78 anos)

A negramina, antigamente, o pessoal, minha mãe, minha avó, tudo na época de Sexta-feira Santa, até eu era criança, esse... ela saia daqui, ia lá nesse morro de Santo Antônio pra pegá essa negramina pra fazê... usá o ano inteiro.

[...] aí pegava a erva, vinha de lá colocava pra secá, aí deixava aí... (Seu José, 54 anos)

Costume... nois saia quinta feira meia noite e ia amanhecer lá na Sexta-feira Maior, em cima do morro, e de dia vinha embora... nesta data é que dá de nois ir lá...então lá tem muito remédio... remédio de todo tipo lá... Nóis pega nesse dia lá, e nois guarda e ela seca... (Seu Davi, 58 anos).

Com relação à quantidade de plantas da espécie no local de origem, há uma contradição entre os entrevistados, pois alguns acham que a quantidade diminuiu principalmente devido às queimadas, e outros acham que o local permanece preservado.

Dos que citaram a época das queimadas e da seca, foi unânime o fato de que a negramina rebrota depois da chuva, pois disseram que o fogo não atinge a raiz da espécie. A seguir, alguns depoimentos sobre a época em que vão buscá-la, e como está o local.

A quantidade de negramina, diminuiu, estão desmatando... (Seu Painha, 78 anos)

Não diminuiu nada a quantidade [...] beira do corgo... rodas de negramina [...] agora cai um pouco da folha porque tá muito quente, mas na beira do corgo sempre tem ele... (Seu Cirilo, 73 anos)

Mas agora tá difícil por causa da desordem dos fogo, tacação de fogo queimou tudo... só depois que chovê é que ela vai brotar... a raiz, ela rebrota... é planta nativa... não diminuiu a quantidade... ela brota, basta começá chovê... (D. Teonila, 75 anos)

Não diminuiu...e outra que o pessoal não pega... só quando é percisão... (Nhá dita, 91 anos)

Agora na época de seca ta difícil... a turma taca fogo no campo, queima tudinho... não acha de jeito nenhum, só na beira do corgo, num corguinho sempre tem... 
Depois que pega fogo, volta a brotar porque as vez não ofende, o fogo passa e não ofende a raiz dela, quando chove ela... (Seu José Narciso, 61 anos)

A quantidade não diminui, porque ela não é muito assim buscada né... E que lá ficou assim um lugar preservado que não tem passagem de fogo, é beira de corgo, ela tem assim aquela conservação, ela praticamente quase que não aumenta e nem acaba...e é só nessa região que deu ela... (Seu Fião, 68 anos)

Tem bastante, mas agora com certeza acho que diminuiu um pouco, acho que é muita seca, e a turma põe fogo lá também né...mas tem...depois que pega fogo rebrota... Nas águas ele reforma tudo... (Seu Davi, 58 anos)

Qualquer época do ano dá, mas as vez o fogo bate neste local, ai o fogo queima, e ai tem que esperar ele chover pra rebrota... (Cirilo Filho, 27 anos)

Sobre o fato de passarem a negramina para pessoas de fora da comunidade, apenas dois entrevistados citaram que pessoas de fora encomendam a planta.

[...] cunhado pegô pro pessoal de Várzea Grande... (Nhá dita, 91 anos)

As criança vai lá panhá... encomenda pra Souza Lima, Cuiabá, pega feixe dele, e o pessoal vem buscá... até do Santo Antônio vem buscá... Sempre pessoal de Souza Lima encomenda pra nóis... (Seu Cirilo, 73 anos)

Além de não conhecerem a $S$. guianensis em seu estado reprodutivo, os entrevistados nunca fizeram tentativas de propagá-la, o que não pode ser interpretado como um descaso com a espécie. Segundo Diegues (2003), para as sociedades tradicionais, o território, diferente das sociedades urbanas, é descontínuo (áreas de pousio, áreas de pesca usadas em apenas parte do ano), ou seja, há um sistema de manejo de recursos naturais marcado pelo respeito aos ciclos naturais, à exploração dentro da capacidade de recuperação das espécies de animais e plantas utilizadas. Este pensamento ficou bem expresso nesta frase de seu Painha: "Onde ter fartura pra panhá ninguém planta..."

Pôde-se observar que os mais jovens já tinham ouvido falar da negramina, mas não sabem sobre o uso, e outros nunca ouviram falar, levando a uma reflexão se o saber local está se perdendo nas novas gerações. Con- forme Amorozo (1996), a passagem de conhecimento é feita a partir de contato intenso entre gerações, principalmente em grupos domésticos e de parentesco. Mas com a vida atual, esse contato é cada vez mais raro. Amorozo (2002) ao pesquisar três comunidades rurais de Santo Antônio do Leverger, afirma que a "modernização" traz consigo novas opções de cuidados com a saúde, e certa desvalorização da cultura local. Os jovens formam o grupo mais sensível, reforçando a tendência à perda ou abandono das práticas tradicionais.

Shanley e Rosa (2006) estudando o conhecimento tradicional numa comunidade na Amazônia afirmam que, apesar dos habitantes locais conhecerem a utilidade de muitas espécies, o uso ativo de certas espécies tem declinado. Tal declínio foi demonstrado através de afirmações frequentes, tais como, minha avó usava, nós não a usamos mais. Particularmente para fins tecnológicos e alguns fins medicinais, muitos usos de plantas existem, principalmente na memória das pessoas, sendo questionável se a identificação das espécies, os regimes de coleta e as técnicas de processamento podem sobreviver mais do que poucas gerações, uma vez que não são praticados.

Para Fleury e Almeida (2007), deve-se também considerar que as populações tradicionais não são exclusivamente aquelas que mantêm padrões imutáveis ao longo dos anos. Pelo contrário, seria justamente na adaptação aos novos contextos, sem ferir seus valores tradicionais, que estaria a sua sustentabilidade.

Essa transformação pode ser observada na comunidade de Bom Sucesso que, mesmo mantendo muitos dos seus costumes, também se caracteriza por uma situação socioeconômica em transformação; o confronto entre modos de pensar e agir tradicionais, e as novas idéias e costumes trazidos com o contato intensificado nas décadas recentes com a sociedade nacional reflete-se também nas questões ligadas à saúde e à doença. Essa idéia foi muito bem traduzida nas palavras do seu José, 54 anos:

Olha hoje não busca mais a negramina, você, sabe... tá tudo moderno... qualquer coisinha já é médico, o pessoal já abandonaram esse lado... 
Deste modo, as formas de manejo dos recursos naturais das comunidades tradicionais, suas formações simbólicas, suas práticas culturais e suas técnicas tradicionais que representam o saber de várias gerações que vivem da e para a natureza (PASA, 2007) precisam ser investigados, documentados e, principalmente, restaurados por meio de pesquisas que dêem suporte para que isso não se perca com o tempo.

\section{Conclusões}

A S. guianensis é conhecida por negramina e a principal forma de preparo é a decocção de suas folhas para se utilizar na forma de banho, especialmente para gripe, febre e dor no corpo. A comunidade não tem conhecimento da propagação e da fenologia dessa espécie. A Comunidade de Bom Sucesso, a exemplo de outras comunidades tradicionais, vive no embate entre as tendências inovadoras e conservadoras, e os mais jovens não a conhecem, ou não fazem uso da espécie.

\section{Referências}

ALBUQUERQUE, U. P. A.; LUCENA, R. F. P.; CUNHA, L, V. F. C. (Orgs.). Métodos e técnicas na pesquisa etnobotânica. 2. ed. Recife: NUPPEA, 2008. 323p.

AMOROZO, M. C. M. Uso e diversidade de plantas medicinais em Santo Antonio do Leverger, MT. Acta Botanica Brasilica, Brasília, DF, v. 16, n. 2, p. 189-203, 2002.

ARJONA, F. B. S.; MONTEZUMA, R. C. M.; SILVA, I. M. Aspectos etnobotânicos e biogeografia de espécies medicinais e/ou rituais comercializadas no mercado de Madureira, RJ. Revista Caminhos da Geografia, Uberlândia, v. 8, n. 23, Edição Especial p. 41-50, 2007.

BOURDY G.; DEWALT S.J.; CHÁVEZ de MICHEL, L.R.; DEHARO E. Medicinal plants uses of the Tacana, an Amazonian Bolivian ethnic group. Journal of Ethnopharmacology, v. 70, p. 87-109, 2000.

BRASIL. Ministério das Minas e Energia. Projeto RADAMBRASIL. Rio de Janeiro, 1982. 544p. (Levantamento de Recursos Naturais, 26).

CABALLERO, J. Maya Homegardens: Past, Present and Future. Etnoecológica 1 (1), p. 35- 54. 1992.

CAMPO, L. M. C. A paisagem simbólica de Bom Sucesso e Limpo Grande, em Várzea Grande-MT. 2006. 184f. Dissertação (Mestrado em Geografia) - Instituto de Ciências Humanas e Sociais, Universidade Federal de Mato Grosso, Cuiabá-MT. 2006.

CARMONA, P. F.; GUARIM NETO, G. As Plantas medicinais, suas formas de uso e aplicabilidade fitoterápica: o saber tradicional. In: Uso da
Biodiversidade: Flora medicinal do cerrado do leste mato-grossense; uma abordagem etnobotânica. Relatório técnico. Instituto de Biociências. Departamento de Botânica e Ecologia. UFMT. 2001.

CHRISTO, A.G.; GUEDES-BRUNI, R.R.; FONSECAKRUEL, V.S. Uso de recursos vegetais em comunidades rurais limítrofes à Reserva Biológica de Poço das Antas, Silva Jardim, Rio de Janeiro: Estudo de caso na Gleba Aldeia Velha. Rodriguésia, Rio de Janeiro-RJ, v. 57, n.3, p. 519-542, 2006.

DIEGUES, A.C. O mito moderno da natureza intocada.3.ed. São Paulo: Hucitec, 2003.169p.

DUARTE, T.G. 2001. Um estudo etnoecológico sobre o uso de recursos vegetais em Nova Xavantina, Mato Grosso. 2001. 135f. Dissertação (Mestrado em Ecologia e Conservação da Biodiversidade) - Instituto de Biociências, Universidade Federal de Mato Grosso, Cuiabá-MT. 2001.

FLEURY, L.; ALMEIDA, J. Populações tradicionais e conservação ambiental: uma contribuição da teoria social. Revista Brasileira de Agroecologia, Porto AlegreRS, v. 2, n. 3, p. 3-19, 2007.

FONSECA-KRUEL,V.S.; PEIXOTO, A. L. Etnobotânica na Reserva Extrativista Marinha de Arraial do Cabo, RJ, Brasil. Acta Botânica Brasilica, Brazília-DF, v. 18, n. 1, p. 177-190. 2004.

FONTELLE, M. G. L. C. Plantas medicinais utilizadas por raizeiros: uma abordagem etnobotânica no conteúdo da saúde e da doença. 1997. 141f. Dissertação (Mestrado em Ecologia e Conservação da Biodiversidade) Instituto de Biociências, Universidade Federal de Mato Grosso, Cuiabá-MT. 2001.

FUNASA, Fundação Nacional de Saúde. Ministério da Saúde. Cemitérios como Fonte Potencial de Contaminação das Águas Subterrâneas Região de Cuiabá e Várzea Grande (MT). Relatório Final. 117 p. Brasília, 2007. Disponível em: <http:/ /www.funasa.gov.br/internet/arquivos/ biblioteca/cemitFonte.pdf > . Acesso em: 30 nov. 2008.

GIMÈNEZ, G. Território, cultura e identidades. La región sociocultural. In: BARRERO, J. M. ROCHE, F.L.; ROBLEDO, A. (Eds.) Cultura y Región. Bogotá: Ces/ Universidad Nacional/Ministerio de Cultura, 2000, p. 87-132.

HANAZAKI, N. Etnobotânica no litoral da Mata Atlântica, 2003. Disponível em: <http://www.comciencia.br>. Acesso em: 15 out. 2008.

HEIDEN, G.; MACIAS, L.; BOBROWSKI, V. L.; IGANCI, J. R. V. Comercialização de carqueja por ervateiros da zona central de Pelotas, Rio Grande do Sul. (nome da revista?) v. 6, n. 2, p. 50-57, 2006.

INMET. Instituto Nacional de Meteorologia do Ministério da Agricultura. Boletim Agroclimatológico. Brasília, v. 30, n. 01-12, 1996.

\section{7.}

. Boletim Agroclimatológico. Brasília, v. 31, n. 01-12,

LORENZI, H.; MATOS F. J. A. Plantas Medicinais no Brasil: Nativas e Exóticas. 1. ed. São Paulo-SP: Nova Odessa / Instituto Plantarum, 2002. 512 p.

MACHADO, A.Q.; ROMIO, A. M. G. CHITARRA, G. S. Seleção de cultivares de tomate para plantio em Várzea GrandeMT. UNIVAG Centro Universitário. Grupo de Produção 
Acadêmica de Ciências Agrárias e Biológicas, Várzea Grande-MT. Disponível em <http:/ / www.abhorticultura. com.br/biblioteca/arquivos/Download/Biblioteca/ 46_0256.pdf>. Acesso em: 24 jan. 2008.

MILLIKEN, W.; ALBERT, B. The use of medicinal plants by the Yanomamy Indians of Brazil. Economic Botany, v.50, n. 1, p.10-25, 1996.

MONTEIRO, U. Várzea Grande passado e presente confrontos 1867-1987. Cuiabá: Ed. Policromos, [19-]. 229 p.

MONTELES, R.; PINHEIRO, C. U. B. Plantas medicinais em um quilombo maranhense: uma perspectiva etnobotânica. Revista de Biologia e Ciências da Terra, v. 7, n. 2, p. 38-48, 2 ${ }^{\circ}$ Semestre 2007.

NORDI, N. et al. Etnoecologia, Educação Ambiental e Desenvolvimento Sustentável. In: SANTOS, J. E. SATO, M. (Orgs). A contribuição da educação ambiental à esperança de Pandora. São Carlos: RIMA, 2001. p. 133-144.

OLIVEIRA, A. G. Avaliação das temperaturas superficiais do solo em relação à conformação urbana existente na Praça do Aeroporto Marechal Rondon em Várzea Grande/MT. 2008. 81f. Dissertação (Mestrado em Física e Meio Ambiente) - Instituto de Ciências Exatas e da Terra, Universidade Federal de Mato Grosso, Cuiabá-MT. 2008.

PASA, M. C. A utilização dos recursos vegetais no Vale do Aricá, Mato Grosso: um estudo etnoecológico. $1999.150 \mathrm{f}$. Dissertação (Mestrado em Ecologia e Conservação da Biodiversidade) - Instituto de Biociências, Universidade Federal de Mato Grosso, Cuiabá-MT. 1999.

PASA, M. C. Um olhar etnobotânico sobre as comunidades do Bambá, Cuiabá-MT. Cuiabá: Editora da UFMT, 2007.143p.

PINTO SOBRINHO, F.A. Conhecimento etnobotânico de mateiros residentes no entorno de Unidades de Conservação no estado do Rio de Janeiro. 2007. 73f. Dissertação (Mestrado em Botânica) - Escola Nacional de Botânica Tropical, Instituto de Pesquisas Jardim Botânico do Rio de Janeiro, Rio de Janeiro-RJ, 2007.

PRANCE, Gillian. T. Ethnobotanical notes from Amazonia, Brazil. Economic Botany. v. 26, n. 3, p. 221237, 1972.

RENNER, S. S.; G. HAUSNER. Monograph of Siparunaceae. Flora Neotropica, 95, 2005. 256p.

ROCHA-COELHO, F. B.; SANTOS, M. G. Plantas medicinais utilizadas pela Comunidade Mumbuca JalapãoTO: Um estudo etnofarmacológico. Pesquisa e Conservação do Cerrado. Disponível em: <http:// www.pequi.org.br/Coelho_\&_Santos.pdf>. Acesso em: 5 maio 2008.
RODRIGUES, L. A; CARVALHO, D. A.; GOMES, L. J.; BOTREL, R. T. 2002. Espécies vegetais nativas usadas pela população local em Luminárias-MG. Boletim Agropecuário. Lavras/MG. n. 52, p. 1-34.

RODRIGUES, V. E. G.; CARVALHO, D. A. Levantamento etnobotânico de plantas medicinais no domínio do cerrado na região do Alto Rio Grande Minas Gerais. Ciência e Agrotecnologia, v. 25, n. 1, p. 102123, jan./fev. 2001.

SANTOS, I. DA S., PEIXOTO, A. L. Taxonomia do gênero Macropeplus Perkins (Monimiaceae, Monimioideae). Rodriguésia, v. 52, n. 81, p. 65-105. 2001.

SCHIMÖLLER, E. Levantamento preliminar das plantas medicinais utilizadas pelos indios Bakairi, Aldeia Pakueran (Paranatinga, Mato Grosso). 1997. 55p. Monografia (Conclusão do Curso de Graduação em Biologia) Instituto de Biociências, Universidade Federal de Mato Grosso, Cuiabá-MT. 1997.

SHANLEY, P.R.; ROSA, N.A. Conhecimento em Erosão: Um inventário Etnobotânico na Fronteira de Exploração da Amazônia Oriental. Boletim do Museu do Pará Emídio Goeldi, Série Cências Naturais, Belém, v. 1, p. 147-171, 2005.

SILVA, J. S. A pesca artesanal, um clamor agroecológico, o território pertencimento de um desafio profissional e a resistência dos saberes geracionais à erosão do patrimônio histórico-cultural-biológico da humanidade. Resumos do V CBA - Palestras. Revista Brasileira de Agroecologia, v. 2, n. 2, p. 1174-1176, Out. 2007.

SOMAVILLA, N. V. Utilização de plantas medicinais por uma comunidade garimpeira do Sudeste mato-grossense, Alto Coité - Poxoréo / Mato Grosso. 1998. 93f. Dissertação (Mestrado em Saúde e Ambiente) - Instituto de Saúde Coletiva, Universidade Federal de Mato Grosso, Cuiabá-MT. 1998.

SOUZA, C. D.; FELFILI, J. M. Uso de plantas medicinais na região de Alto Paraíso de Goiás, GO, Brasil. Acta Botanica Brasílica, v. 20, n. 1, p. 135-142, 2006.

SOUZA, L. F. de. Levantamento etnobotânico na localidade de São Gonçalo, Cuiabá, Mato Grosso, Brasil. 1992. 41f. Monografia (Conclusão do Curso de Graduação em Biologia)-Instituto de Biociências, Universidade Federal de Mato Grosso, Cuiabá-MT. 1992.

STANLEY VIGNERON, M.; DEPARIS, X.; DEHARO, E.; BOURDY, G. Antimalarial remedies in French Guiana: A knowledge attitudes and practices study. Journal of Ethnopharmacology, v. 98, p. 351-360, 2005. 